JKM (Jurnal Kebidanan Malahayati),Vol 7,No.4.Oktober 2021,

ISSN (Print) 2476-8944 ISSN (Online) 2579-762X, Hal 865-868

\title{
TINGKAT PENGETAHUAN LANSIA TENTANG HIPERTENSI BERHUBUNGAN DENGAN KEJADIAN HIPERTENSI
}

\author{
Diyanah Kumalasary ${ }^{1}$, Tesa Seftiana ${ }^{2 *}$
}

Sekolah Tinggi Ilmu Kesehatan Muhammadiyah Cirebon

*Korespondensi email seftianatessa@gmail.com

\section{ABSTRACT LEVEL OF ELDERLY KNOWLEDGE ABOUT HYPERTENSION RELATED TO HYPERTENSION EVENTS}

Background: Hypertension is a persistent increase in blood pressure with systolic pressure above 140 $\mathrm{mmHg}$ and diastolic pressure above $90 \mathrm{mmHg}$. According to WHO, around 972 million people worldwide or $26.4 \%$ worldwide suffer from hypertension, this figure is likely to increase to $29.2 \%$ in 2025 . According to the 2013 Basic Health Research, it is known that the prevalence of hypertension in Indonesia is $25.8 \%$ with the highest prevalence in Bangka Belitung at 30.9\%, followed by South Kalimantan at 30.8\%, East Kalimantan at 29, 6\%, and West Java is a province that places the fourth position at 29.4\% (Ministry of Health, 2013). Notoatmodjo in 2010 explained that hypertension prevention behavior is an important part that must be considered by avoiding bad habits such as drinking coffee, smoking, irregular exercise, drinking alcohol and eating foods that contain fat. Hypertension can be overcome, one of which is a healthy lifestyle, this can be applied if people with hypertension have sufficient knowledge

The purpose of the study: to determine the relationship between the level of knowledge of the elderly about hypertension with the incidence of hypertension in Lemahabang sub-district in 2020.

Methods: This study uses an analytical method with a cross sectional approach. The subjects of this study were the elderly aged 60 years and over. Based on the results of the chi-square test, the $P$ value $(\alpha=<0.05)$ was obtained.

Results: The results of the study on the level of knowledge of respondents about hypertension obtained good knowledge levels as many as 11 respondents (22\%), sufficient knowledge levels as many as 24 respondents (48\%), and less knowledge levels as much as 15 (30\%). 30 respondents (60\%) had hypertension, while 20 respondents (40\%).

Conclusion There is no relationship between the knowledge of the elderly related to hypertension with the incidence of hypertension in Lemahabang sub-district

Suggestion: it is hoped that the community will increase their level of knowledge regarding hypertension so that they can prioritize health services so that the community, especially the elderly, can choose and determine a good and correct way of life. Keywords: Knowledge, Hypertension

Keywords Knowledge, Hypertension, Elderly

\section{ABSTRAK}

Latar belakang : Hipertensi adalah suatu peningkatan tekanan darah persisten dengan tekanan sistolik diatas $140 \mathrm{mmHg}$ dan tekanan diastilok di atas $90 \mathrm{mmHg}$.Menurut WHO, di seluruh dunia sekitar 972 juta orang atau $26,4 \%$ di seluruh dunia mengidap hipertensi, angka ini kemungkinan akan meningkat menjadi $29,2 \%$ ditahun 2025. Menurut Riset Kesehatan Dasar 2013 diketahui prevalensi hipertensi di Indonesia sebesar 25,8\% dengan prevalensi tertinggi terdapat di Bangka Belitung sebesar 30,9\%, diikuti kalimantan selatan sebesar 30,8\%, kalimantan timur sebesar $29,6 \%$, dan jawa Barat merupakan provinsi yang menempatkan posisi ke empat sebesar 29,4\% (Depkes RI, 2013). Notoatmodjo tahun 2010 menjelaskan bahwa perilaku pencegahan hipertensi adalah salah satu bagian penting yang harus diperhatikan dengan menjauhi kebiasaan yang kurang baik seperti minum kopi, merokok, olahraga tidak teratur, minum alkohol dan makan makanan yang mengandung lemak. Hipertensi dapat di atasi salah satunya dengan pola hidup yang sehat, hal ini bisa diterapkan bila penderita hipertensi memiliki pengetahuan yang cukup

Tujuan penelitian : untuk mengetahui hubungan antara tingkat pengetahuan lansia mengenai hipertensi dengan kejadian hipertensi di kecamatan Lemahabang tahun 2020. 
Metode : Penelitian ini menggunakan metode analitik dengan pendekatan cross sectional. Subjek penelitian ini adalah lansia yang berumur 60 tahun ke atas. Berdasarkan hasil uji chi-square di dapatkan nilai $P$ value $(\alpha=<0,05)$

Hasil : Hasil penelitian tingkat pengetahuan responden tentang hipertensi didapatkan tingkat pengetahuan baik sebanyak 11 responden (22\%), tingkat pengetahuan cukup sebanyak 24 responden (48\%), dan tingkat pengetahuan kurang sebanyak $15(30 \%)$.Dari hasil penelitian kejadia hiprtensi pada lansia didapatkan yang mengalami hipertensi sebanyak 30 responden $(60 \%)$ sedangkan yang tidak hipertensi sebanyak 20 responden $(40 \%)$.

Kesimpulan Tidak terdapat hubungan antara pengetahuan lansia terkait hipertensi dengan kejadian hipertensi di kecamatan Lemahabang

Saran: diharapkan masyarakat lebih meningkatkan tingkat pengetahuannya terkait hipertensi sehingga dapat memprioritaskan pelayanan kesehatan agar masyarakat khususnya lansia dapat memilih dan menentukan cara hidup yang baik dan benar.Kata kunci : Pengetahuan, Hipertensi

Kata Kunci Pengetahuan,Hipertensi,Lansia

\section{PENDAHULUAN}

Seseorang dikatakan lansia ialah apabila berusia 60 tahun atau lebih, karena faktor tertentu tidak dapat memenuhi kebutuhan dasarnya baik secara jasmani, rohani maupun sosial (Nugroho, 2012). Semakin bertambah tua umurnya, proporsi lansia yang mengalami keluhan kesehatan semakin besar. Sebanyak $37,11 \%$ penduduk pra lansia mengalami keluhan kesehatan dalam sebulan terakhir, meningkat menjadi $48,39 \%$ pada lansia muda, dan proporsi tertinggi pada lansia tua yaitu sebesar $64,01 \%$. Kemunduran fungsi organ tubuh khususnya pada lansia menyebabkan kelompok ini rawan terhadap serangan berbagai penyakit, salah satunya yaitu hipertensi. Hipertensi atau tekanan darah tinggi adalah suatu peningkatan tekanan darah persisten dengan tekanan sistolik diatas 140 $\mathrm{mmHg}$ dan tekanan diastilok di atas $90 \mathrm{mmHg}$.

keluhan kesehatan tidak selalu mengakibatkan terganggunya aktivitas sehari-hari, namun terjadinya keluhan kesehatan dan jenis keluhanyang dialami oleh masyarakat dapat menggambarkan tingkat/derajat kesehatan secara kasar. Bertambahnya umur, fungsi fisiologis mengalami penuruanan akibat proses penuaan sehingga penyakit tidak menular banyak muncul pada lanjut usia. Masalah degeneratif juga menurunkan daya tahan tubuh sehingga lansia rentan terkena infeksi penyakit menular. Notoatmodjo tahun 2010 menjelaskan bahwa perilaku pencegahan hipertensi adalah salah satu bagian penting yang harus diperhatikan dengan menjauhi kebiasaan yang kurang baik seperti minum kopi, merokok, olahraga tidak teratur, minum alkohol dan makan makanan yang mengandung lemak.

Hipertensi dapat di atasi salah satunya dengan pola hidup yang sehat, hal ini bisa diterapkan bila penderita hipertensi memiliki pengetahuan yang cukup.

Menurut WHO, di seluruh dunia sekitar 972 juta orang atau $26,4 \%$ di seluruh dunia mengidap hipertensi, angka ini kemungkinan akan meningkat menjadi 29,2\% ditahun 2025. Menurut Riset Kesehatan Dasar 2013 diketahui prevalensi hipertensi di Indonesia sebesar 25,8\% dengan prevalensi tertinggi terdapat di Bangka Belitung sebesar $30,9 \%$, diikuti kalimantan selatan sebesar $30,8 \%$, kalimantan timur sebesar $29,6 \%$, dan jawa Barat merupakan provinsi yang menempatkan posisi ke empat sebesar 29,4\% (Depkes RI, 2013).

Tujuan khusus dari penelitian ini adalah untuk mengetahui gambaran pengetahuan, kejadian dan hubungan pengetahuan lansia mengenai hipertensi di Kecamatan Lemahabang tahun 2020

\section{METODE PENELITIAN}

Design penelitian ini menggunakan rancangan observasional disertai metode analitik pendekatan yang digunakan dalam penelitian ini adalah cross sectional adalah dimana mengambil variabel independen dan dependen dalam satu waktu. Mengambil variabel pengetahuan tentang hipertensi dan menilai kejadian hipertensi menggunakan kuesioner dalam satu waktu (Notoatmodjo, 2010).

Subjek penelitian ini adalah lansia yang berumur 60 tahun ke atas.

\section{HASIL DAN PEMBAHASAN}

Kecamatan Lemahabang merupakan salah satu kecamatan di Kabupaten Cirebon dengan luas wilayah 22,65 $\mathrm{Km}$ persegi. Melalui kantor kecamatan ini, warga dapat mengurus berbagai bentuk perizinan. 


\section{JKM (Jurnal Kebidanan Malahayati),Vol 7,No.4.Oktober 2021, ISSN (Print) 2476-8944 ISSN (Online) 2579-762X, Hal 865-868}

Puskesmas sindanglaut merupakan puskesmas yang paling terdekat dari kantor Kecamatan Lemahabang. Lokasinya bertempat di di Desa Lemahabang, Kecamatan Lemahabang, Kabupaten Cirebon.

Kecamatan Lemahabang secara struktural membawahi 13 Desa/Kelurahan yaitu : Asem, Cipeujeuh Kulon, Cipeujeuh wetan, Lemahabang Kulon, Leuwidingding, Lemahabang Wetan, Sarajaya, Sigong, Belawa, Picungpugur, Tuk Karangsuwung, Wangkelang, Pengambilan data dilakukan pada tanggal 12 Januari sampai tanggal 04 Maret 2021 di Kecamatan Lemahabang, dengan menggunakan instrumen penelitian berupa kuesioner dengan jumlah lansia 50 orang.

Hasil penelitian tingkat pengetahuan responden tentang hipertensi didapatkan tingkat pengetahuan baik sebanyak 11 responden (22\%), tingkat pengetahuan cukup sebanyak 24 responden $(48 \%)$, dan tingkat pengetahuan kurang sebanyak $15(30 \%)$.

Dari hasil penelitian kejadian hiprtensi pada lansia didapatkan yang mengalami hipertensi sebanyak 30 responden $(60 \%)$ sedangkan yang tidak hipertensi sebanyak 20 responden (40\%).

Berdasarkan hasil uji chi-square di dapatkan nilai $P$ sebesar $0,000(\alpha=<0,05)$, dari hasil ini dapat ditarik kesimpulan bahwa tidak ada hubungan antara pengetahuan dengan kejadian hipertensi. Hal ini di dukung penelitian yang dilakukan oleh Taukhit (2009).

\section{PEMBAHASAN}

Berdasarkan hasil penelitian dari 50 responden ternyata didapatkan tingkat pengetahuan baik sebanyak 11 responden (22\%), tingkat pengetahuan cukup sebanyak 24 responden (48\%), dan tingkat pengetahuan kurang sebanyak 15 (30\%).

Tingkat pengetahuan ini dipengaruhi oleh banyak faktor. Menurut Notoatmodjo (2003), tingkat pengetahuan dipengaruhi oleh tingkat pendidikan, pengalaman, informasi, media massa, kultur budaya, tingkat sosial ekonomi, dan petugas kesehatan. Pengetahuan merupakan dominan yang paling penting dalam membentuk tindakan seseorang (overt behavior).

Faktor lain yang turut mempengaruhi tingkat pengetahuan responden dalam penelitian ini adalah tingkat sosial ekonomi/penghasilan. Menurut Notoatmodjo (2003). Tingkat kemampuan seseorang untuk memenuhi kebutuhan mempengaruhi tingkat pengetahuan yang didapat. Semakin tinggi penghasilan seseorang maka semakin mudah seseorang untuk mendapatkan pengetahuan dan informasi.

Menurut hasil penelitian hipertensi dan tidak hipertensi data menunjukan bahwa sebagian responden yang tidak mengalami hipertensi sebesar $40 \%$ (sebanyak 20 responden), sedangkan yang mengalami hipertensi sebesar $60 \%$ (sebanyak 30 responden).

Dari hasil penelitian diketahui bahwa dari 50 responden yang diklasifikasikan menjadi 2 golongan yaiitu hipertensi dan tidak hipertensi. Golongan hipertensi yang berpengetahuan baik sebanyak 7 responden (sebesar 23,3\%), yang berpengetahuan cukup sebanyak 13 responden (sebesar 43,3\%), dan yang pengetahuannya kurang sebanyak 10 responden (sebesar 33,3\%). Untuk golongan yang tidak mengalami hipertensi yang berpengetahuan baik sebanyak 8 responden (sebesar 40\%), yang berpengetahuan cukup sebanyak 7 orang (sebesar $35 \%$ ), dan yang berpengetahuan kurang sebanyak 5 orang (sebesar 25\%). Mengacu pada hasil penelitian ini, bahwa tidak ada hubungan antara pengetahuan dengan kejadian hipertensi . hal ini di dukung penelitian yang dilakukan oleh Taukhirt (2019).

\section{KESIMPULAN}

Tidak terdapat hubungan antara pengetahuan lansia terkait hipertensi dengan kejadian hipertensi di kecamatan Lemahabang

\section{SARAN}

Diharapkan masyarakat lebih meningkatkan tingkat pengetahuannya terkait hipertensi sehingga dapat memprioritaskan pelayanan kesehatan agar masyarakat khususnya lansia dapat memilih dan menentukan cara hidup yang baik dan benar.

\section{DAFTAR PUSTAKA}

Sidabutar, R. P., Wiguno P. Hipertensi essensial. In: IImu Penyakit Dalam Jilid II. Soeparman, Sarwono Waspadji. Balai Penerbit FK-UI, 1999. P:205-222

Susalit E. Hipertesni Primer dalam Buku Ajar IImu Penyakit Dalam Jilid II. Edisi Ketiga. Balai Penerbit FK-UI, Jakarta

National Institutes of Health: The Seventh Report of The Joint National Commite on Prevention, Detection, Evaluation, and Treatment of High Blood Pressure, NIH Publication, November 2003

Noer MS: Buku Ajar IImu Penyakit Dalam, Edisi Ketiga, Jilid Kedua, Balai Penerbit FKUI, 2003 


\section{Diyanah Kumalasary, Tesa Seftiana}

Mengenal Hipertensi (Editorial). 2002. http://id.novartis.com

Sheps, S. G. (2005). Maryo clinic hipertensi; mengatasi tekanan darahtinggi. Jakarta: Intisari Mediatama.

Sigarlaki, H. J. O 1995. Faktor-faktor resikopenderita hipertensi di RSU FK-UKI. Program Studi Pascasarjana IImu Kesehatan Masyarakat, Jakarta. 1995: 52 - 53

Tierney LM, McPhee SJ, Papadakis MA. Systemic Hypertension. In: Current Medical Diagnosis \& Treatment. 41st Edition. Mcgraw-Hill Companies. 2002. p:459-469

Mansjoer A, Suprohalita, Wardhani WL, Setiowulan W,: Kapita Selekta Kedokteran, Jakarta, Media AesculapiusFKUI, 2001

http://fkm.unsrat.ac.id/wpcontent/uploads/2015/2015/05/ARTIKELJURNAL-RILIE.pdf. Di ambil dari artikel journal 2015

Lalu Febrian P.P. hubungan Pengetahuan Tentang Hipertensi dengan Perilaku Pencegahan Primer di Desa Nyatnyono Kecamatan Ungara Barat. Program Studi Kesehatan Masyarakat STIKES Ngudi Wluyo Ungaran: 2013

Sefriami. (2010). Hubungan Tingkat Pengetahuan dengan Pengelolaan Hipertensi pada Penderita Hipertensi di Rt 10-12 Kelurahan Pandeyan Umbulharjo Kota Yogyakarta, 10.

Christy, D. (2012). Gambaran Tingkat Pengetahuan tentang Hipertensi pada Masyarakat yang Merokok di Rw 01 Kelurahan Pondok Cina, Beji, Depok. 63-64.

Nastiti, F. (2018). Hubungan Pengetahuan dengan Sikap Lansia Terhadap Diet Hipertensi Di Panti Tresna Werda Magetan.

Misbah. (2006). Hubungan antara Kebiasaan Hidu dengan Kejadian Hipertensi pada Lansia. 6567.
Suprtayana, D, \& Putri, S. (2020). Hubungan Tingkat pengetahuan Lansia tentang Hipertensi dengan Kepatuhan Diet Hipertensi di Panti Sosial Tresna Werdha Jara Mara Pati Buleleng. Volume 3. 44.

Mujiran, dkk. (2019). Hubungan Tingkat pengetahuan tentang Hipertensi dengan Sikap dalam Pencegahan Komplikasi Hipertensi pada Lansia Peserta Prolanis UPT Puskesmas Jenawi Karanganyar. Jurnal IImiah Kesehatan dan Aplikasi. Volume 7(2). 36-38.

Ragil Catur, dkk. ( 2018). Hubungan Tingkat Pengetahuan Lansia tentang Hipertensi dengan Kepatuhan dalam Meminum Obat di Posyandu Lansia Drupadi. Volume 3, Nomor 1, 2018. 218.

Limbong, dkk. (2016). Hubungan Pengetahuan dan Sikap dengan Kejadian Hipertensi di wilayah kerja Puskesmas Tateli Kabupaten Minahasa. Volume 7, nomor 4, 4-5

Astiari, T. (2016). Faktor-faktor yang mempengaruhi Kejadian Hipertensi pada Laki-laki Dewasa di Puskesmas Payangan, Kecamatan Papayang Kabupaten Gianyar. 10-20

Sulistiyono, Y. (2013). Gambaran Asupan Zat Gizi dan Aktivitas Fisik Mahasiswa IImu Keolahragaan Universitaas Pendidikan Indonesia. 19-29.

Puguh Suharso, Metode Penelitian Kuantitatif Untuk Bisnis: pendekatan Filosofi dan Praktif, (Jakarta: PT Indeks, 2009), hal 3.

Febriynti, K. (2019). Hubungan Tingkat Pengetahuan Tentang Hipertensi dengan Sikap dalam Pencegahan Komplikasi Hipertensi di Ruang Poli Penyakit Dalam RSUP H Adam Malik Medan Tahun 2019. 824. 